\title{
Security Gradient and National Defense - The Optimal Choice between a Draft Army and a Professional Army
}

\author{
Vesa Kanniainen \\ University of Helsinki, HECER, and CESifo \\ and \\ Staffan Ringbom \\ Hanken School of Economics and HECER
}

Discussion Paper No. 376

January 2014

ISSN 1795-0562

HECER - Helsinki Center of Economic Research, P.O. Box 17 (Arkadiankatu 7), FI-00014 University of Helsinki, FINLAND, Tel +358-9-191-28780, Fax +358-9-191-28781,

E-mail info-hecer@helsinki.fi, Internet www.hecer.fi 


\title{
Security Gradient and National Defense - The Optimal Choice between a Draft Army and a Professional Army*
}

\begin{abstract}
The earlier work on the optimal design of the national security has focused on the opportunity cost of the draft in terms of foregone human capital formation. The current paper introduces the national security into the welfare analysis missing from the earlier work. This creates a trade-off between the private goods and the security as a public good in the social cost-benefit analysis. There are three major results. First, and arising from the intergenerational interaction, it is optimal to introduce a pay to the young generation when in duty even by resorting to a distortive tax. Second, when optimizing the size of the army, the optimal choice between the draft army and the professional army depends on the risk class of the country. A security gradient arises. Third, the choice is linked to the size and the quality of the reserve generated by the two approaches.
\end{abstract}

JEL Classification: H2O, H57, I21, D63

Keywords: national security, draft, professional army, risk class

Vesa Kanniainen

Department of Political and Economic Studies

University of Helsinki

P.O. Box 17 (Arkadiankatu 7)

FI-00014 University of Helsinki

FINLAND

e-mail: vesa.kanniainen@helsinki.fi
Staffan Ringbom

Department of Economics

Hanken School of Economics

P.O. Box 479 (Arkadiankatu 7)

FI-00101 Helsinki

FINLAND

e-mail: staffan.ringbom@hanken.fi

* The authors are grateful to Roope Uusitalo for several suggestions and to Rune Stenbacka for comments on the earlier draft. We also thank Juha-Matti Lehtonen and Juha Antero Mäkinen for their help. 


\section{Introduction}

For each nation, the national security represents a public good. There are various ways of providing it. In 1970, the President's Commission on An AllVolunteer Armed Force (Gates Commission) launched its by now the classic analysis with the aim of eliminating the draft in the USA. The message of the Commission was well-taken by President Richard Nixon: the draft was replaced by an all-volunteer substitute. The arguments put forward by the Commission were built both on the concerns of inefficiency and inequity characterized by the draft. One of the influential members of the Commission, Milton Friedman had strongly argued against the US draft since 1967 (Friedman, 1967). ${ }^{1}$ The attitudes were also influenced by the catastrophic Vietnam war. Many countries in particular in the Western Europe have followed the US lead ${ }^{2}$, most recently Sweden $(2010)^{3}$ and Germany (2011). ${ }^{4}$

The widely-held view among the economic profession appears to be that unlike the draft, the professional army is cost-efficient (see Warner and Asch (2001) for a review). The implications of the draft as a hidden tax were formally analyzed by Poutvaara and Wagener (2007), PW subsequently. They introduced a striking proposition that the utility level in the steady state of an economy with a draft system always falls short of the utility level of an economy with a professional army. This conclusion is based on the following crowding-out mechanism: the effort into human capital formation through education and, consequently, the output and the consumption as well as the maximally obtainable utility level with a draft system always falls short of the utility level of an economy with a professional army. As both solutions to the military delay the education investment for the young involved, the individuals entering the professional army with a market salary welcome a positive tax due to the discounting benefit. They are paid for their service during the early stage of their life-cycle. Though they subsequently are taxed on their civil income to finance the next generation of the professional army they welcome such an inter-generational transfer. However, their interest is time-inconsistent: when old, they would prefer not to pay the tax. Thus, there is a built-in conflict between the generations in the

\footnotetext{
${ }^{1}$ The US discussion started with Friedman (1967) but actually there is a non-published paper by young Gary Becker (1957) who was strongly against the draft. His paper was published 50 years later (Becker, 2007).

${ }^{2}$ We hasten to notice, however, that these examples may not be the most appropriate ones. Since the establishment of NATO in 1949, the Western European member countries have effectively been free riding on the US military power (cf. Sandler and Hartley (2001)).

${ }^{3}$ Sweden has practically abolished her infantry army. The obvious interpretation is that Sweden is free riding on the military budget of her Eastern neighbor, Finland as a buffer state in the north and the NATO Baltic states in the south. In March 29, 2013, the Russian air force sent two Backfire bombers and four fighters closed to the Swedish Gotland to test the preparedness of the Swedish air base to meet the foreign military aircrafts. The Swedish air force was unable to send its air force in the air as the pilots were at leisure. The NATO fighters from an air base in Lithuania, in stead, took off to check the Russian aircrafts. The chief of the Swedish army stated in 2013 that if attacked by an enemy, Sweden needs help from outside within a week. This points to NATO and Norway, in particular. The Swedish secret cooperation with NATO over a long period is publicly known.

${ }^{4}$ It is worth pointing out that there are about 50.000 US soldiers in Germany!
} 
professional army.

The PW-result is derived in a context where the social welfare criterion fails to capture the proper valuation of national security as a public good. Their model abstracts from the trade-off between the consumption of the market output as a private good and national security as a public good and appears valid only in a world with everlasting peace. ${ }^{5}$ The empirical evidence has widely supported this conclusion (see PW for references). Yet, the most recent work by Card and Cardoso (2011) using Portuguese data appears to challenge this view. ${ }^{6}$

The current paper provides a new perspective into the issue of an optimal approach to the optimal design of national security. The need for such an analysis arises for two reasons. One is empirical, one is theoretical. From the empirical point of view, there are countries which persistently appear not to follow the US lead of an all-volunteer armed force. Those countries include Israel in particular but also some European countries (Finland, Austria, Switzerland, Norway, Denmark, Estonia, Greece, Ukraine, Belarus, Russia and Turkey). These cases suggest that the US solution may not be universally optimal. Indeed, in Israel young men are servicing the security of the country for three years and the females for 21 months. Moreover, her defense budget amounts to 7 per cent of GDP. In Finland, the polls suggest that 72 per cent of the population favors the draft in the national defense. In Austria, the corresponding figure is 60 per cent. In the 2013 referendum in Switzerland, 73 per cent of people stood behind the draft rejecting the professional army. The European countries which have abolished the draft have found another solution on their national security: relying on NATO as a joint alliance.

There is also a theoretical reason for reconsideration the issue: the economic tools of public economic are today more advanced than they were in the early 1970s when the Gates Commission launched its report.

Our modeling approach differs from that of Poutvaara and Wagener (2007). They run the comparison between the draft army and the professional army by assuming that the military output is given, and that it equals the size of the active army. In our paper, we introduce explicitly the national security as a public good which needs to be produced. A draft and a tax-financed professional army are alternative institutional arrangements to address the problem of security design. We identify countries in terms of their risk class in the face of an outside threat. On the way towards such an analysis, we however first reconsider the discounting argument. The draft indeed represents an implicit

\footnotetext{
${ }^{5}$ From a broader perspective, the national security has two dimensions, the internal and the external one. In most, if not in all countries, the policy force is run by the public sector through hirings from the labor market. The provision of internal security thus represents an area where the PW result quite generally holds. In some cases, the social order is strengthened or fully provided privately by private clubs like the mafia.

${ }^{6}$ They found that the average impact of the military service for men who were working prior to age 21 is close to zero. However, there is a significant 4-5 percentage point impact on men with only primary education, coupled with a zero-effect for men with higher education. The positive impact on less-educated men suggests that the mandatory service can be a valuable experience for those who might otherwise spend their careers in low-level jobs.
} 
tax. However, as it is well-understood, the citizens of a country with an allvolunteer army face another tax, an income tax, say. What this suggests is that from the efficiency point of view, the country with an all-volunteer army faces a double distortion, a tax on education and a tax on income required to service the military. Consequently, the discounting benefit associated with the pay to the military should be balanced against the welfare loss. ${ }^{7}$

What we find is that in the utility comparison, the PW result holds. At the equilibrium, the benefit of the young today equals the discounted tax cost to be paid subsequently and accompanied with the lower education and civil wage. Moreover, those who outsource the military service to the professionals, are able to raise their education effort which enhances the national value-added. This implies that the rewards on the military and the civilians become differentiated in the way which we show below. There is a utility-maximizing positive tax rate on old to finance the service of the young. However, even in that case it is utilityincreasing to pay the young (draftees) an intergenerational transfer, but a low one! Subsequently, we ask by how much the citizens of a country in a particular risk class are willing to pay as an insurance against an outside threat. This is an optimal tax problem which we state a trade-off between an income (wealth) effect and the security effect. We arrive at what we call a security gradient along which the countries can be located in terms of their security index. The size of the reserve and its quality determining the defense capacity qualify the optimal choice between the draft and the professional army. Our numerical simulations illustrate the trade-off along the security gradient showing that above a critical risk class of countries, it is the draft which strictly dominates while for countries in a lower risk class, it is the professional army which dominates.

As an illustration of our security gradient, think of Vatican with no outside threat and no military army, The Republic Uzupis with an army of 11 soldiers ${ }^{8}$, or Monaco with a professional army of roughly 200 soldiers. It would certainly be inefficient to have a draft in those cases. Think then about Israel, a country surrounded by a number of enemies. It could not handle its security unless based on the draft. The USA is a safe country in the sense that no enemy can conquer its territory. It does not need a draft to protect its boundaries. It needs professionals to avoid another Pearl Harbor and the threat from missiles, like during the Cuban crisis. Not the same with Finland. Her collective memory dates back to the 14 th century and extends over the subsequent centuries with repeated wars between her Eastern neighbor, Russia, and Sweden, with Finland being located between those countries. ${ }^{9}$

Our paper is structured as follows. In Section 2, we introduce the basic infrastructure of the model. In Section 3, the optimal size of the army is derived as a solution to an optimal tax problem. The proper social welfare function in

\footnotetext{
${ }^{7}$ This view actually is consistent with some loose remarks by Friedman (1967) and the Gates Commission (1970).

${ }^{8}$ This republic locates in Vilnius of Lithuania declared itself an independent republic in 1997. No government has recognized its independence.

${ }^{9}$ The start of the Second World War, know in Finland as the winter war, was however, an exception in that the Stalin's Red Army attacked Finland in 1939.
} 
an uncertain world is introduced in Section 4. The welfare comparisons between the draft and a professional army are reported in Section 5. Section 6 briefly concludes.

\section{The Basic Model}

\subsection{The basic architecture of the model}

To have a proper economic comparison between the draft and the professional army, we compare armies which are of an equal size and have access to the same technology and the military training. We therefore initially compare a 100 per cent draft with no pay with a 100 per cent professional army where soldiers are paid, say an exogenous wage. ${ }^{10}$ In the case of a professional army, the country may, however, want to reduce the size of the military. Then, the welfare analysis shall incorporate explicitly the national security.

The basic architecture of the model follows that of PW but with some key adjustments to capture the national security. There are two overlapping generations of size one each of which consists of identical individuals. Apart from the educational investment, a two-period model is needed here for an additional reason absent from that of the PW-model: the fundamental role played by the reserve in the national defense. The national security is assumed to depend both on factors exogenous to the country, her location dictating the risk class of the country and on the defense strategy of the country.

In each of the two periods of their life, the individuals have available a certain time endowment normalized to one. When young, a fraction $\alpha$ will be spent on education. The human capital, the productivity $w(e)$ is conditional on the educational investment $e$. The productivity is strictly increasing in $e$. There is a strictly increasing and convex utility cost, $c(e)$, associated with education. We assume that it takes $d<1$ unit of time to train the young for national defense. In both systems, the rest of the time, $1-d-\alpha$ is used for working when young; the working time is 1 when during the second period. Everyone in the model therefore has a soldier-civil career. After the military service, this generation makes up the reserve army. ${ }^{11}$ When born, the individuals are homogeneous with no skill differences. The wage elasticity of the supply of labor is taken to be unity. ${ }^{12}$ Labor demand is perfectly elastic at the market wage. Private

\footnotetext{
${ }^{10}$ When introducing the draft in our model, we speak for the sake of the modeling reasons of 100 percent draft. In practice, the draft can be much smaller. Moreover, a pure draft is a simplification as some professional always need to be involved.

${ }^{11}$ Should a military conflict outbreak, the relative initial loss inflected on the draft army with reserve is smaller than is the loss inflicted on the professional army. This follows from the substantial size difference of the defense troops. It also means that after the initial loss, the strategy based on the guerrilla war is available in the case of the draft system while no such option is available under the professional army. These differences amount to a drastic difference in the ex ante incentives to initiate an attack by a potential enemy.

${ }^{12}$ Becker (2007) and the Gates Commission (1970) recognized that the supply elasticity tends to exceed one (may be around 1.25) which makes the professional army at the margin more expensive. We abstract from this mechanism. The skill differences would suggest that
} 
output and the national security are taken to be complements in the welfare of individuals. ${ }^{13}$

The professional army is financed by a tax, say $\tau$, on income. The case of the draft is obtained as a special case by choosing $\tau=0$. Ultimately, then the question of the choice between the two militaries is a matter of an optimal tax problem. Moreover, as the tax is not collected from individuals when young and in service ${ }^{14}$, the choice represents an interest conflict between young versus old.

Abstracting for a moment from the national security - to be introduced below - the utility of each citizen is given by the utility net of the education cost as in $\mathrm{PW}$,

$$
u(e)=-c(e)+Y(w(e))
$$

where $Y$ is the life-time income of individuals. With a professional tax-financed military and with the discount factor $\gamma=(1+r)^{-1}$ with $r>0$ denoting the discount rate, the after-tax life-time income for each soldier-civil is

$$
Y^{p}(w(e))=p+w(e)(1-\tau)[(1-d-\alpha)+\gamma],
$$

where $p$ is the pay to individuals during their service. ${ }^{15}$

Denoting $\Gamma=1+\gamma-\alpha$, the steady state-value of the life-time income is

$$
Y^{p}(w(e))=p+e(1-\tau)(\Gamma-d)
$$

With little loss of generality and with no qualitative importance, we introduce parameterizations

$$
\begin{gathered}
c(e)=\frac{1}{2} e^{2} \\
w=e .
\end{gathered}
$$

\subsubsection{Education incentive}

The return on education over the remaining employment career determines the education incentive. Backward induction thus has to be employed to solve for the education incentive as the military pay $p$ is bygone after the service. Then, from $\max _{e} u(e)$, the education effort under the professional army is

$$
e^{p}=(1-\tau)(\Gamma-d)
$$

while it is

$$
e^{d}=\Gamma-d
$$

the individuals with a high skill in military take the army career in the first place.

${ }^{13}$ We point out an important limitation of the current analysis. We do not introduce in the current paper the technology intensity of an army. The technology is in today's world important. The reason for this omission is that the issue between the draft and the professional army has abstracted from the technological aspects.

${ }^{14} \mathrm{~A}$ tax on them is irrelevant as in the case of a large army, it is fully refunded to them.

${ }^{15}$ Here $p$ is the net pay. If the military pays an income tax its tax is transferred back to itself without the discounting benefit. 
in the case of the draft. The education effort thus is linear in the subsequent working career.

\subsubsection{Military pay}

The income tax to finance the military pay is levied on the young in their first working period and on the old in the second period of their life-cycle. In the steady state with a constant civil wage, the tax base thus is

$$
B=w(e)(1-d-\alpha)+w(e) .
$$

With a large army, this is allocated to the individuals in the military the size of which is 1 . Therefore, the pay to each soldier is

$$
p=\tau w(e)(2-d-\alpha) .
$$

The productivity and the civil wage level are $w^{p}=(1-\tau)(\Gamma-d)$. Then, after substitutions, the total life-time income of each soldier-civil is

$$
Y^{p}=(1-\tau)(\Gamma-d)[\tau(2-d-\alpha)+(1-\tau)(\Gamma-d)]
$$

\subsection{Draft and professional army: utility comparison}

Allowing for the cost of education, the welfare under a professional army is

$$
u^{p}=-\frac{1}{2}(1-\tau)^{2}(\Gamma-d)^{2}+(1-\tau)(\Gamma-d)[\tau(2-d-\alpha)+(1-\tau)(\Gamma-d)] .
$$

This can be re-written as

$$
u^{p}=(\Gamma-d)\left[\frac{1}{2}(1-\tau)^{2}(\Gamma-d)+(1-\tau) \tau(2-d-\alpha)\right]
$$

while the utility of each individual under the draft, obtained by introducing $\tau=0$, is

$$
u^{d}=\frac{1}{2}(\Gamma-d)^{2}
$$

With the parameter values which we adopt subsequently below $\Gamma=1.2333, d=$ 0,4 , the utility level under the draft is $u^{d}=0.347104$.

The utility under a professional army is a second-degree function in the tax rate, i.e. a parable. Evaluating its derivative at the origin, $\tau=0$, it is

$$
\left.\frac{\partial u^{p}}{\partial \tau}\right|_{\tau=0}=(\Gamma-d)(2-\Gamma-\alpha) .
$$

This is positive when $2-\Gamma-\alpha>0$ which is satisfied with the parameter values which we adopt below, $\Gamma=1.2333, d=0,4, \alpha=0.6$, and is its value is $0.13891 .{ }^{16}$ This means that starting with a draft, when a professional army

\footnotetext{
${ }^{16}$ Were this condition not satisfied, the professional army were never welfare-increasing.
} 
is introduced based a small tax on civil income and hence a small pay to the military while in service, the introduction is welfare-increasing. However, because the $u^{p}$ - function is a parable in the tax rate, it has a unique maximum as the second derivative, $(\Gamma-d)(\Gamma+d+2 \alpha-4)$ is everywhere negative. Its maximum is obtained at

$$
\tau^{\max }=\frac{\Gamma+\alpha-2}{\Gamma+d+2 \alpha-4}
$$

provided that $\Gamma+d+2 \alpha-4 \neq 0$ which holds when the second-order condition is satisfied. Inserting the numerical values, the utility maximizing tax rate turns out to be $\tau=0.14288$. With this tax rate, the utility gain is greatest from moving from the draft to a professional army, or which is equivalent, paying the draftees a fixed lump sum pay, $p$. Its magnitude can be found by solving for the civil wage, $w^{p}=0.71423$ and using the tax rate $\tau=0.14288$ to solve for the pay to the military, $p=0.10204$.

Proposition 1. An intergenerational transfer from the old to the young in service is utility-increasing.

What is the intuition? The welfare effects of the pay to the draftees depend on three mechanisms. First, as the tax burden is levied on the old generation and transferred to the young when in service, the latter will benefit through the discount effect identified by Poutvaara and Wagener (2007). This suggests that impatient individuals prefer a future tax in order to have a greater immediate benefit. However, and second, a high tax rate creates a distortion reducing the return on education and thereby the education incentive. Third, by reducing the education education, it reduces the cost of education. The last two effects cancel to some extent each other in the private cost-benefit calculation. The driving force is the first effect, the intergenerational transfer to the military when in duty, $(1-\tau) \tau$ essentially. With a small tax rate, it is positive. A shift from a draft with a zero pay to the draft ( "all-participating professional army") with a positive pay is not Pareto-improvement neither is a shift to a tax rate which exceeds $\tau=0.14288$. However, having establish a tax rate at $\tau=0.14288$ the intergenerational equilibrium satisfies the Pareto-efficiency. ${ }^{17}$

\section{Optimizing the Professional Army}

A full-scale professional army is expensive. We consider therefore the case where the size of the army is determined as part of the welfare optimum. Assume thus that the government hires a fraction of the young generation, $n<1$, in each period to be trained for the national defense. The training takes $d<1$ units of time and provides the same military skill as the training in the draft. After the military training, the young get enrolled in an education program for $\alpha$ unit of time entering into the civil career in the labor market. Those who do not enter the army, get enrolled in the education program immediately, study $\alpha$ units

\footnotetext{
${ }^{17}$ At this stage, we point out that the utility-maximizing tax rate 0.14288 is no upper limit in the welfare analysis below where the national security is introduced in the welfare analysis.
} 
of time and work in the labor market $1-\alpha$ and 1 units of time over the two periods.

We denote the army salary by $w^{m}$ per unit of time and link it to the subsequent productivity and the civil salary of the ex-soldiers by $w^{c} .{ }^{18}$ Then, the ex-soldiers from both age cohorts generate a post-army private output

$$
y_{1}^{p}=n(1-d-\alpha) w^{c}+n w_{-1}^{c} .
$$

Those who do not enter the army, enter immediately the education program lasting $\alpha$ units of time, then entering the labor force. As their civil working career is longer, their productivity is greater as the productivity is determined in a forward-looking manner and is determined by the length of the working career. Their salary per unit of time is denoted by $w^{p}$. The output of this non-military group of two cohorts per period is ${ }^{19}$

$$
y_{2}^{p}=(1-n)(1-\alpha) w^{p}+(1-n) w_{-1}^{p} .
$$

The private output in each period therefore is

$$
\begin{aligned}
y^{p} & =y_{1}^{p}+y_{2}^{p} \\
& =n(1-d-\alpha) w^{c}+n w_{-1}^{c}+ \\
& +(1-n)(1-\alpha) w^{p}+(1-n) w_{-1}^{p} .
\end{aligned}
$$

When the national security of a country is based on the professional army, the individuals will have to make up their career choice. The non-arbitrage condition implies that the life-time income, adjusted for the cost of education effort, has to be equalized over both careers.

We assume that both the military and the civilians pay the income tax. The life-time after-tax income of the (full) civilian is

$$
Y_{2}^{p}=(1-\tau) w^{p} \Gamma .
$$

These full-civilians thus invest in education by maximizing

$$
u\left(e^{p}\right)=-c\left(e^{p}\right)+(1-\tau) e^{p} \Gamma .
$$

The optimal education effort is

$$
e^{p}=(1-\tau) \Gamma .
$$

Then, the civil wage is

$$
w^{p}=(1-\tau) \Gamma
$$

\footnotetext{
${ }^{18}$ The military salary $w^{m}$ is thus endogenous though it is not related to labor productivity as it is derived from the contribution of the soldiers to the national security. The civil salary $w^{c}$, however, is the market wage and therefore related to the labor productivity.

${ }^{19}$ In the model, people are homogeneous before the career choice. If inherent productivity differences exist it becomes more expensive at the margin to recruit soldiers as a premium wage is introduced. The Gates Commission (1970) recognized that this tends to increase the cost of the professional army.
} 
and the life-time income of the full-civilians is

$$
Y_{2}^{p}=(1-\tau)^{2} \Gamma^{2} .
$$

As those with the military career are paid $w^{m}$ over $d$ units of time and after that civil wage $w^{c}$ in two stages, their lifetime income is

$$
\begin{aligned}
Y_{1}^{p} & =d(1-\tau) w^{m}+(1-d-\alpha)(1-\tau) w^{c}+\frac{1}{1+r}(1-\tau) w^{c} \\
& =d(1-\tau) w^{m}+(1-\tau)(\Gamma-d) w^{c}
\end{aligned}
$$

We now need to solve for the military salary $w^{m}$ and the subsequent civil salary $w^{c}$. Using backward induction, we start with the latter.

The utility from the post-military civil education is

$$
u\left(e^{c}\right)=-c\left(e^{c}\right)+(1-\tau)(\Gamma-d) w^{c} .
$$

Maximizing,

$$
e^{c}=(1-\tau)(\Gamma-d)<e^{p}
$$

and

$$
w^{c}=(1-\tau)(\Gamma-d)<w^{p} .
$$

The reason for a lower post-military salary for soldiers is the shorter civil career making the military invest less in their civil education.

However, their life-time utility cannot be lower; it has to be equalized with that in the civilian career. We thus require the following no-arbitrage condition over the life-cycle in the two careers,

$$
Y_{1}(p)-\frac{1}{2}\left(e^{c}\right)^{2}=Y_{2}(p)-\frac{1}{2}\left(e^{p}\right)^{2} .
$$

As the after-military earning, to be denoted by $w^{m c}$, is lower for the exsoldiers, this has to be compensated by the salary during the military - yet, the lower education cost relaxes somewhat this requirement. The life-time income of the military-civilians is

$$
\begin{aligned}
Y_{1}(p) & =d(1-\tau) w^{m}+(1-\tau)(\Gamma-d) w^{m c} \\
& =d(1-\tau) w^{m}+(1-\tau)^{2}(\Gamma-d)^{2} .
\end{aligned}
$$

The non-arbitrage conditions requires

$$
d(1-\tau) w^{m}+(1-\tau)^{2}(\Gamma-d)^{2}-\frac{1}{2} e^{m c 2}=(1-\tau)^{2} \Gamma^{2}-\frac{1}{2} e^{p 2} .
$$

Solving then for the military wage,

$$
w^{m}=\frac{(1-\tau)^{2} \Gamma^{2}-\frac{1}{2}\left(e^{p}\right)^{2}-(1-\tau)^{2}(\Gamma-d)^{2}+\frac{1}{2}\left(e^{c}\right)^{2}}{d(1-\tau)}
$$


With the costs of education,

$$
\begin{gathered}
e^{p}=(1-\tau) \Gamma . \\
e^{c}=(1-\tau)(\Gamma-d),
\end{gathered}
$$

we obtain

$$
w^{m}=\frac{(1-\tau)^{2} \Gamma^{2}-\frac{1}{2}((1-\tau) \Gamma)^{2}-(1-\tau)^{2}(\Gamma-d)^{2}+\frac{1}{2}((1-\tau)[\Gamma-d])^{2}}{d(1-\tau)} .
$$

Evaluating,

$$
w^{m}=(1-\tau)\left(\Gamma-\frac{d}{2}\right),
$$

we find that the pay for soldiers exceeds their pay in the post-military job,

$$
w^{c}<w^{m}
$$

However, it is is less than the wage for the full-civilians,

$$
w^{m}=(1-\tau)\left(\Gamma-\frac{d}{2}\right)<(1-\tau) \Gamma=w^{p} .
$$

Somewhat unexpectedly, we have proved:

Proposition 2. The soldiers in the professional army make a greater earning during their military than they subsequently make in the civil labor market. Arising from the differences in the length of civil training and working career, the full-civilians make a greater pay than the soldiers.

\subsection{Tax revenue}

The tax revenue is collected from five groups of individuals. In each period, the soldiers pay a tax on their army salary and the subsequent civil salary. The soldiers from the previous period pay a full tax on their civil earnings. In addition, the young full-civilians pay the tax both as young and as old. The tax base thus is

$$
B=n d w^{m}+n(1-d-\alpha) w^{c}+n w_{-1}^{m c}+(1-n)(1-\alpha) w^{p}+(1-n) w_{-1}^{p}
$$

In the steady state, the tax revenue from the total civil output is

$$
B^{*}=n d w^{m}+n(2-d-\alpha) w^{m c}+(1-n)(2-\alpha) w^{p} .
$$

Recalling the wage rates solved above,

$$
\begin{gathered}
w^{p}=(1-\tau) \Gamma . \\
w^{c}=(1-\tau)(\Gamma-d) .
\end{gathered}
$$




$$
w^{m}=(1-\tau)\left(\Gamma-\frac{d}{2}\right)
$$

and inserting,

$$
B^{*}=(1-\tau)\left[n d\left(\Gamma-\frac{d}{2}\right)+n(2-d-\alpha)(\Gamma-d)+(1-n)(2-\alpha) \Gamma\right]
$$

The steady state tax revenue therefore is

$$
T^{*}=\tau B^{*} \text {. }
$$

This tax revenue finances the cost of the army of size $n$ once in duty,

$$
T^{*}=n w^{m} d .
$$

Inserting and solving for the size of the army gives

$$
n(\tau)=(2-\alpha) \Gamma \frac{\tau}{b-\tau a},
$$

where we have introduced a notation

$$
\begin{gathered}
a=\left(\Gamma-\frac{d}{2}\right) d+(2-d-\alpha)(\Gamma-d)-(2-\alpha) \Gamma \\
b=\left(\Gamma-\frac{d}{2}\right) d .
\end{gathered}
$$

The expression for the army above answers the question: given the tax rate $\tau$, what is the size of the army which the tax can finance given that (i) the imposed tax distorts the investment in education both of the full-civilians and the ex-soldiers and (ii) the life-time utility of the soldiers and the full-civilians have to be equal?

\subsection{A numerical example}

At this point it is helpful to produce an illustrative numerical example of the connection between the tax rate $\tau$ and the army size $n(\tau)$. In particular, it is necessary to make sure that values for the parameter values exist which make $n(\tau)<1$. It should be clear that one cannot hope to introduce "realistic" parameters in a two-period economy model as the real economy represents, say a 10 period case. Picking up illustrative parameter values, one can, however, examine the logic of the model.

We pick up values $\alpha=0.6, d=0.4$, and $r=0.20$. Then $\Gamma=1.2333$ and $a=-0.48000, b=0.41332$. Subsequently, we use below these same parameter values to illustrate the welfare levels at the welfare optimum. As $a<0$, we know that $b-\tau a>0$. We can therefore find out the comparative statics of the army size

$$
\frac{\partial n(\tau)}{\partial \tau}=(2-\alpha) \Gamma \frac{b}{(b-\tau a)^{2}}>0
$$




$$
\frac{\partial^{2} n(\tau)}{\partial \tau^{2}}=(2-\alpha) \Gamma \frac{2 a b}{(b-\tau a)^{3}}<0 .
$$

Remark 1. The size of the army is strictly concave in the tax rate.

Thus, the tax revenue is a limited source to finance the army as implied by the concavity! Introducing then some illustrative examples, say $\tau=0.05$, $\tau=0.15$ and $\tau=0.20$, we find that such tax rates are able to finance an army of size $n=0.19, n=0.53$ and $n=0.68$. A large army with $n=1$ would necessitate a tax rate $\tau=0.33155$. This is illustrated in Figure 1 .

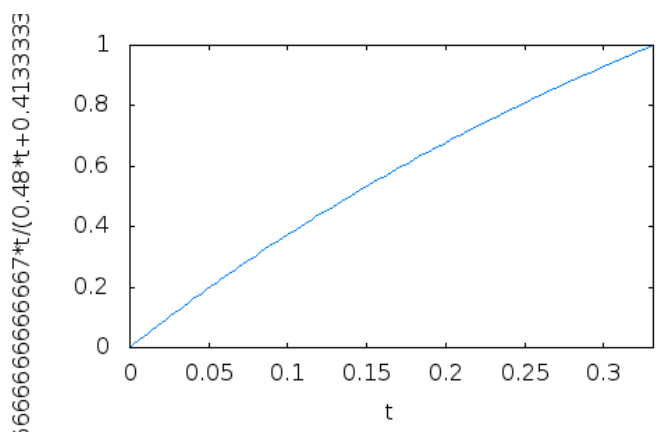

Figure 1: Army size as a function of the tax-rate

\section{National Security as a Public Good}

\subsection{The trade-off between the income and security effects in social welfare}

To solve for the optimal size of the army and to have the welfare comparison between the draft and the professional army, we introduce a relevant social welfare function. The decision makers are assumed to value positively the private consumption of citizens dictated by their income opportunities. Moreover, we will introduce a model of delegated security provision where the public sector provides the national security for the citizens as a public good. Extending the above model to incorporate the national security $s$ as a public good, we rewrite the utility of individual $i$ as ${ }^{20}$

$$
u^{i}=u\left(\tilde{Y}_{i} ; s\right)
$$

where $\widetilde{Y}_{i}$ is the discounted life-time net wealth of the individuals (net of the cost of education). Then, we adopt a utilitarian welfare criterion

$$
W=W\left(\int_{0}^{1} u\left(\widetilde{Y}_{i} ; s\right) d i\right) .
$$

\footnotetext{
${ }^{20}$ It is appropriate to view the national security as a feeling of safety.
} 
In the draft system, the individuals are identical, and the social welfare is

$$
W^{d}=W\left(u\left(\widetilde{Y}^{d} ; s\right)\right) .
$$

Such a welfare function captures the trade-off between private goods and the national safety as a public good. Further constraints are available for the welfare function. Positive consumption is not possible if the national security is lost. Moreover, national security has no value of its own if the consumption opportunities vanish. In order to make both private consumption and national security necessities, we work out the social welfare using a multiplicative social welfare function. With the diminishing marginal utility of wealth at a rate, say $0<\rho<1$, such a function can be presented as

$$
W^{d}=\frac{1}{1-\rho}\left(\tilde{Y}^{d}\right)^{1-\rho} s .
$$

Introducing a logarithmic transformation,

$$
v^{d}=\log W^{d}=(1-\rho) \log \left(\widetilde{Y}^{d}\right)-\log (1-\rho)+\log (s) .
$$

In the case of the professional army, the utilitarian welfare is

$$
W^{p}=W\left(n \widetilde{Y}^{c}+(1-n) \widetilde{Y}^{p} ; s\right)
$$

where $\widetilde{Y}^{c}$ and $\widetilde{Y}^{p}$ are the discounted life-time net wealths of the civilians and the military.

The national security is determined by an outside threat and internal defense capacity. The location of the country plays a decisive role in the determination of the outside threat. We introduce a notion of risk class of countries indexed by $\beta$,

$$
\beta \epsilon\left[\beta_{L}, \beta_{H}\right] .
$$

Consequently, we let $\beta_{L}$ denote the risk class of a country with a low risk of a military conflict and $\beta_{H}$ the risk class of a country with a high risk of a military conflict, and $\beta_{M}$ between those a medium risk class. ${ }^{21}$ We let $q^{d}, q^{p}$ denote the defense capacities being determined by two alternative options, the draft and the professional army. We introduce a simple additive parametrization for the national security function,

$$
s^{i}=\beta_{i}^{-1}+q^{j}, \quad i=H, M, L, j=d, p .
$$

The location effect and the investment in the defense capacity are viewed as substitutes. Take two examples. Israel can be viewed as a high $\beta$-country with a highly disadvantageous location. Therefore, she has to rely on her defense capacity as the major source of national security. Take Sweden as another

\footnotetext{
${ }^{21}$ Membership in the NATO as a joint venture makes many European - but not all - countries low risk countries. They are therefore able to free ride on the resources of the joint venture.
} 
example. She has a more advantageous location. Therefore, she can afford of relying on a limited defense capacity. ${ }^{22}$ Taking again the logarithms,

$$
v^{p}=\log W^{p}=\log \left(n u^{d}+(1-n) u^{p}\right)-\log (1-\rho)+(1-\rho) \log (s) .
$$

From above, the life-time income and education cost of the civilians under the professional army were found to be

$$
\begin{gathered}
Y_{2}^{p}=(1-\tau)^{2} \Gamma^{2} . \\
c\left(e^{p}\right)=\frac{1}{2}(1-\tau)^{2} \Gamma^{2} .
\end{gathered}
$$

Thus, their net utility (discounted life-time net wealth) is

$$
u_{2}^{p}=Y_{2}^{p}-c\left(e^{p}\right)=\frac{1}{2}(1-\tau)^{2} \Gamma^{2} .
$$

By arbitrage, the military must have the same net utility.

\subsection{Reserves - a stylized approach}

The defense capacity $q$ is determined by the number of trained soldiers consisting in the draft system from the young in the training process and the old as a reserve. $^{23}$ We make a stylized assumption that the quality of the reserve is $\lambda>0$ in the draft and $\mu>0$ of the trained army in the case of the professional army. Under both types of army, the size and the quality of reserve should be optimized. ${ }^{24}$ We, however, introduce a natural and stylized model of the reserve. The steady state defense capacities under the two defense options are assumed to be

$$
\begin{aligned}
& q^{d}=1+\lambda \\
& q^{p}=(1+\mu) n, \quad \mu>0 .
\end{aligned}
$$

\footnotetext{
${ }^{22}$ The last time Sweden participated in a war was its war against Norway in 1814. Sweden was able to keep herself outside the war both in the First and in the Second World War. Moreover, during the Cold War, Sweden was able to stay neutral. With the recent Russian activity close to the Swedish territory, Sweden has decided to move some of her tanks to Gotland island. Moreover, some suggestions have been made to re-introduce the army in Sweden.

${ }^{23}$ In the analytic model, the size of reserve equals the size of the young generation. In practice, the reserve is much greater in the draft system because the number of successive generations alive is large. In Finland, for example, the size of the reserve is 10 times greater than the number of soldiers trained each period. Appendix A presents data on the size of the army and the reserve in a sub-set of countries. It is worth noticing that the size of the reserve is much greater in countries with a draft (Austria, Denmark, Estonia, Finland, Norway, Switzerland) than in countries with a professional army.

${ }^{24}$ The military has to be trained prior to any conflict. There may be differences in the training process. More important than the quality of training is, however, the motivation. A number of examples including the Vietnam war witness that highly motivated fighters are more successful than a less motivated army even equipped with a better weapons.
} 
While allowing for the depreciation of skills both in the draft army and in the professional army, we will examine the case where the depreciation of the quality is the same,

$$
\lambda=\mu .
$$

\subsection{Welfare under draft}

In the case of the draft in our model, no social optimization takes place: when young, every citizen is trained for the public defense. What remains to be done is to calculate the value of the social welfare. From above, we know that

$$
u(d)=\left(\frac{1}{2}\right)(\Gamma-d)^{2} .
$$

Then, the social welfare in the draft system for countries in various risk classes is given by

$$
v^{d}=\underbrace{(1-\rho) \log \left[\left(\frac{1}{2}\right)(\Gamma-d)^{2}\right]-}_{\text {"wealth effect" }} \frac{\log (1-\rho)}{+\underbrace{\log \left[\beta_{i}^{-1}+(1+\lambda)\right]}_{\text {"security effect" }}, \quad i=H, M, L .}
$$

We work with the same parameter values introduced above $\alpha=0.6, d=0.4$ and $r=0.20$. Then $\Gamma=1.2333$ and $a=-0.48000, b=0.41332$. We carry out the calculation where $\rho=0.05$ and the quality of the reserve is $\lambda=0.5$. We take illustrative values for the risk class of the country i.e. $\beta_{L}=1$ for a lowrisk country, $\beta_{M}=10$ for a medium-risk country and $\beta_{H}=100$ for a high-risk country. The welfare levels, when decomposed into the wealth effect and the security effect are summarized in Table 1 . We notice that the wealth effect is

Table 1: Welfare under draft

\begin{tabular}{|c|c|c|c|}
\hline & $\beta_{L}=1$ & $\beta_{M}=10$ & $\beta_{H}=100$ \\
\hline \hline Wealth effect, & -0.953615 & -0.953615 & -0.953615 \\
\hline Security effect, & 0.916291 & 0.470004 & 0.412110 \\
\hline Total effect, $v^{d}$ & -0.037324 & -0.483611 & -0.541505 \\
\hline
\end{tabular}

independent of the country-specific risk while the security effect declines with the country-specific risk.

\subsection{Optimizing the professional army size}

As the size of the army was given by

$$
n=(2-\alpha) \Gamma \frac{\tau}{b-\tau a},
$$


the social welfare under the professional army is

$$
\begin{aligned}
& v^{p}=\underbrace{(1-\rho) \log \left[\frac{1}{2}(1-\tau)^{2} \Gamma^{2}\right]-\log (1-\rho)}_{\text {"wealth effect" }} \\
& +\underbrace{\log \left[\beta_{i}^{-1}+(1+\mu)(2-\alpha) \Gamma \frac{\tau}{b-\tau a}\right]}_{\text {"security effect" }} \cdot i=H, M, L .
\end{aligned}
$$

The optimal size of the army is obtained from working out first the optimal tax rate from the first-order condition

$$
\frac{\partial v^{p}}{\partial \tau}=0
$$

Evaluating $\partial v^{p} / \partial \tau$, one finds that it consists of two conflicting effects,

$$
\frac{\partial v^{p}}{\partial \tau}=-\frac{2(1-\rho)}{1-\tau}+\left(\frac{1}{b-\tau a}\right) \frac{(1+\mu)(2-\alpha) \Gamma b}{\beta^{-1}(b-\tau a)+(1+\mu)(2-\alpha) \Gamma \tau}
$$

The first term, the welfare effect provides the (logarithmic) utility loss from the income tax. The second term, the security effect, provides the (logarithmic) security gain from the tax-financed army. It is straight forward to observe that both terms in (38) are decreasing in $\tau \in[0,1)$, and that $\lim _{\tau \uparrow 1} \partial v^{p} / \partial \tau=-\infty .^{25}$ Therefore, a tax rate satisfying $\partial v^{p} / \partial \tau=0$ in the interval $[0,1)$ maximizes $v^{p}$. Evaluating the derivative $\partial v^{p} / \partial \tau$ at $\tau=0$, yields

$$
\left.\frac{\partial v^{p}}{\partial \tau}\right|_{\tau=0}=-2(1-\rho)+\frac{\beta}{b}(1+\mu)(2-\alpha) \Gamma .
$$

This is positive for countries in a high-risk class with a sufficiently high $\beta$. As a numerical example, take take the case which we studied above, $\alpha=0.6$, $\Gamma=1.2333, a=-0.48000, b=0.41332, \rho=0.05$, and $\mu=0.5$ Then $\partial v^{p} / \partial \tau>0$ at $\tau=0$ only if $\beta>0.303217$. For the countries in a low-risk class with $\beta<$ 0.303217 , the optimal tax rate can never be positive. We can thus make the following remark,

Remark 2. For countries with strong basic security, there is no case for a military army.

From now on, we consider the professional army case where the optimal army size is positive.

Requiring $\partial v^{p} / \partial \tau=0$ and multiplying the denominators, the first order condition is expressed in a linear-quadratic form:

$$
\begin{aligned}
& -2(1-\rho)(b-\tau a)\{(b-\tau a)+\beta(1+\mu)(2-\alpha) \Gamma \tau\} \\
& +\beta(1-\tau)(1+\mu)(2-\alpha) \Gamma b=0 .
\end{aligned}
$$

\footnotetext{
${ }^{25}$ Recall that $a<0$.
} 
If there exists a root in $(0,1)$ it is also maximizing $v^{p}$. From the first order condition $\partial v^{p} / \partial \tau=0$, we can solve for the implicit derivative $\partial \tau / \partial \beta$,

$$
\frac{\partial \tau}{\partial \beta}=-\frac{\frac{\partial}{\partial \beta}\left(\frac{\partial v^{p}}{\partial \tau}\right)}{\frac{\partial}{\partial \tau}\left(\frac{\partial v^{p}}{\partial \tau}\right)} .
$$

We observe that $\partial v^{p} / \partial \tau$ in (38) is strictly decreasing in $\tau \in[0,1)$, and linearly increasing in $\beta$. Therefore, $\frac{\partial}{\partial \tau}\left(\frac{\partial v^{p}}{\partial \tau}\right)<0$ and $\frac{\partial}{\partial \beta}\left(\frac{\partial v^{p}}{\partial \tau}\right)>0$, and consequently $\partial \tau / \partial \beta>0$ along the first order condition $\partial v^{p} / \partial \tau=0$. An increase in $\beta$ will automatically increase the optimal tax rate. Next, as $\partial n / \partial \tau>0$, we observe using the chain rule that

$$
\frac{\partial n}{\partial \beta}=\frac{\partial n}{\partial \tau} \frac{\partial \tau}{\partial \beta}>0
$$

We have arrived at a relationship between the risk class of the country and the optimal army size. We may call this relationship a security gradient and state

Proposition 3. (Security Gradient) The optimal size of the military depends positively on the risk class of the country.

The relationship between the risk class and the army size is illustrated in Figure 2.

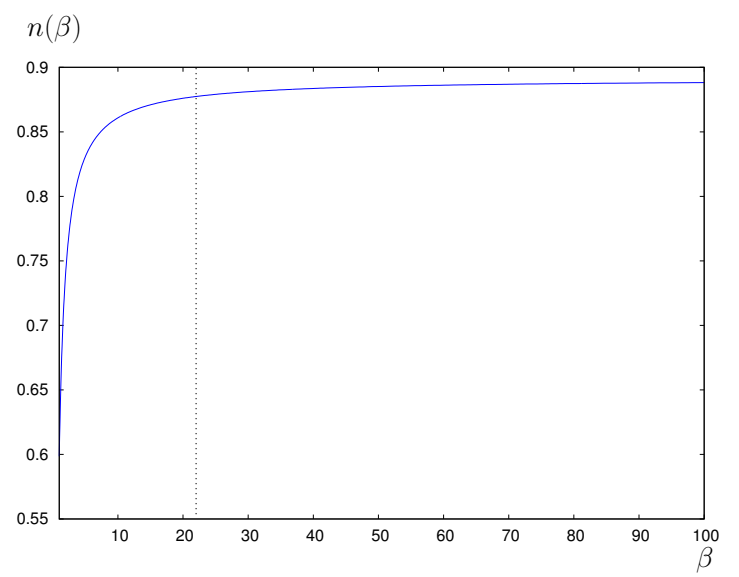

Figure 2: Army size, $n$, as a function of the risk class, $\beta$.

\section{Welfare comparison}

We now run the welfare comparison concerning the army design. The welfare under professional army was expressed in Equation (36). 
The parameters we have adopted are $\alpha=0.6, \Gamma=1.2333, a=-0.48000, b=$ 0.41332 , and $\rho=0.05$. Assume again that $\mu=0.5$. Moreover, take again the risk class as $\beta_{L}=1$ for a low-risk country, $\beta_{M}=10$ for a medium-risk country and $\beta_{H}=100$ for a high-risk country.

Under professional army, the welfare levels decomposed into the wealth-effect and the security effect are summarized in Table 2.

Table 2: Welfare with a professional army

\begin{tabular}{|c|c|c|c|}
\hline & $\beta_{L}=1$ & $\beta_{M}=10$ & $\beta_{H}=100$ \\
\hline \hline Wealth effect & -0.567072 & -0.809062 & -0.839056 \\
\hline Security effect & 0.640714 & 0.330257 & 0.294396 \\
\hline$v^{p}$ & 0.073642 & -0.478805 & -0.544660 \\
\hline
\end{tabular}

When we compare the welfare components in Table 1 and Table 2 we observe that the professional army beats the draft in the wealth levels. This is consistent with the finding of PW. The security effect, however, is smaller in all cases under the professional army when compared with the draft army. This follows both from the army size effect and the role played by the reserve. Introducing the national security as a public good and evaluating its role in the welfare analysis thus refutes the mainstream economists' thinking that a professional army always beats in the welfare comparison the draft army.

The total welfare under professional army and draft army is depicted in Figure 3 . We observe that there exist a cut-off point in the graph at $\beta \approx 21.3$, below which a professional army is preferred, and above which a draft army is preferred. $^{26}$

Finally, notice that all the above simulations are based on specific numerical values for the parameters. Of course, they cannot be taken literally as no real-life calibration is possible in a two-period model. When carrying out such simulations, we found, for example that the welfare comparison is sensitive to the $\rho$-parameter stating the declining marginal utility of wealth. With linear preferences, i.e. $\rho=0$, the professional army always beats the draft. With even a slightly declining marginal utility (we worked with $\rho=0.05$ ), the draft beats the professional army for high-risk countries. With a somewhat stronger decline in the marginal utility, say $\rho=0.1$, the draft always beats the professional army. While these effects no doubt are rather intuitive they also provide support on the view that the national security cannot be left outside when designing the solution to defense architecture.

\footnotetext{
${ }^{26}$ Recall, as we have shown in Section 2.2 , that the welfare under a draft army can be boosted by introducing "a small pay" in form of a tax-transfer to those in draft. This is not done in the comparison above. Therefore, our comparison is biased in favor for a professional army.
} 


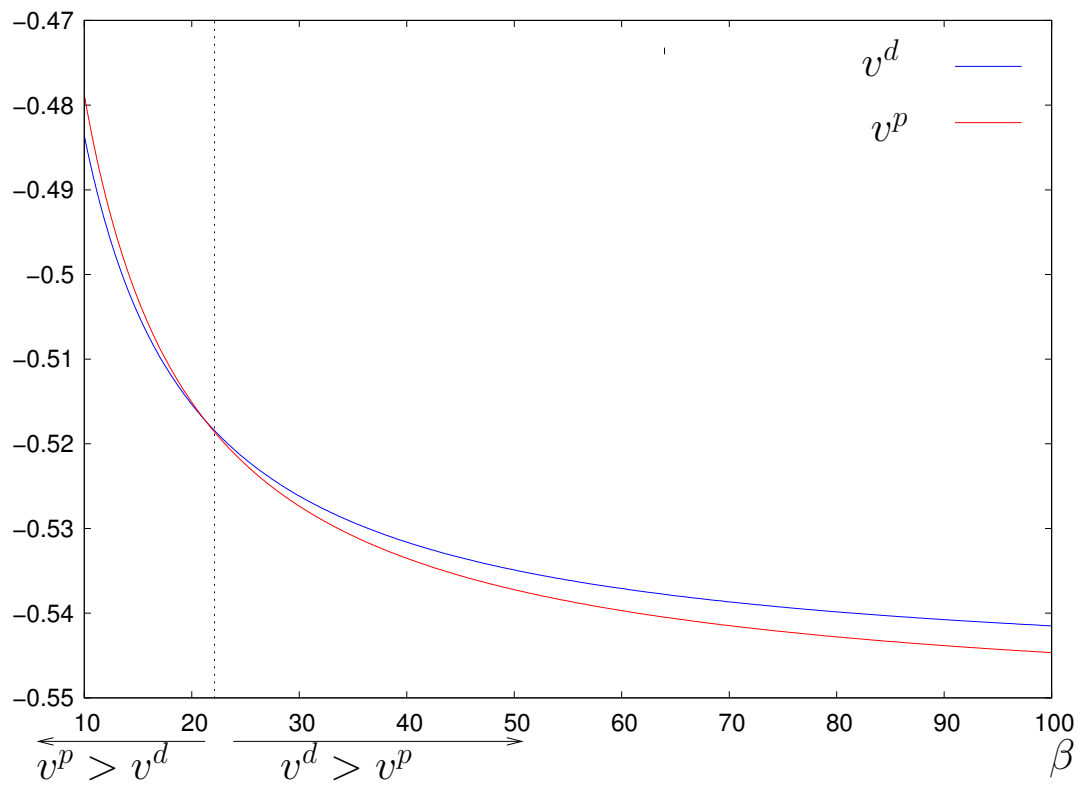

Figure 3: Comparison of welfares under professional army and draft army.

\section{Conclusion}

The dominating view among economists has focused on the superiority of a professional army over a draft army. This conclusion has been challenged in this paper. The proposition may hold as an optimal solution for internal threat in the society to be controlled by a policy force and hired from the labor market. In the case of an outside threat, we have shown that the proposition fails when the required tax revenue to finance the professional army is high and when the threat to the national security is properly introduced. The empirical evidence provided by the literature in favor of the professional army probably is inappropriate if no allowance is made to the distinction between high-risk and low-risk countries nor to the alliance effect allowing for the opportunism option. Throughout the paper, we have assumed that the relevant non-arbitrage military salary is not affected by the risk for external intervention. In high risk countries, there is a non-negligible risk of an early death in duty. This should be reflected as a premium on the military salary. We also assumed that the relative defense capacities of the reserves with a draft army and a professional army are the same $(\mu=\lambda)$. However, from Appendix A we observe that the defense capacity of the reserve under draft is higher. These aspects further strengthens the case for a draft army in high-risk countries though we have not introduced these aspects in our model. When carrying out such simulations, we found, for example that the welfare comparison is sensitive to the marginal utility of wealth. These effects provide support on the view that the national security cannot be left outside 
when designing the solution to defense the architecture.

\section{References}

The military balance 2012: The annual assessment of global military capabilities and defence economics, 2012.

G. Becker. The case against the draft. Hoover digest 2007 No 3, Hoover, 2007. Based on unpublished ideas from 1957.

D. Card and A. R. Cardoso. Can compulsory military service increase civilian wages? evidence from the peacetime draft in portugal. Working Paper 17694, NBER, 2011.

M. Friedman. Why not a volunteer army? New Individualist Review, 4(4):3 6, 1967.

T. S. Gates, T. Curtis, F. Dent, M. Friedman, C. Greenwalt, A. Greenspan, A. Gruenther, S. Herbits, T. Hesburgh, J. Holland, J. Kemper, J. Noble, L. Norstad, W. A. Wallis, and Wilkins Roy. The Report of the President's Commission on an All-Volunteer Armed Force, 1970.

Panu Poutvaara and Andreas Wagener. To draft or not to draft? inefficiency, generational incidence, and political economy of military conscription. European Journal of Political Economy, vol 23(4):975 - 987, 2007.

T. Sandler and K. Hartley. Economics of alliances: The lessons for collective action. Journal of Economic Literature, XXXIX:869 - 896, 2001.

J.T. Warner and J. Asch. The record and prospects of the all-volunteer military in the united states. Journal of Economic Perspectives, 15:169-192, 2001. 


\section{A Appendix: The sizes of the active army and reserve in selected countries}

$\begin{array}{llll}\text { Country } & \text { Active } & \text { Reserve } & \text { Reserve/Active-ratio } \\ \text { Austria } & 23250 & 176450 & 7.59 \\ \text { Denmark } & 16450 & 53500 & 3.25 \\ \text { Estonia } & 5750 & 30000 & 5.22 \\ \text { Finland } & 22200 & 354000 & 15.95 \\ \text { Norway } & 24450 & 45250 & 1.85 \\ \text { Swizerland } & 23100 & 157100 & 6.80 \\ & & & \\ \text { Belgium } & 32650 & 1400 & 0.04 \\ \text { France } & 228850 & 29650 & 0.13 \\ \text { Germany } & 196000 & 40320 & 0.21 \\ \text { Italy } & 181450 & 18300 & 0.10 \\ \text { Netherlands } & 37400 & 3200 & 0.09 \\ \text { Poland } & 96000 & 0 & 0.00 \\ \text { Portugal } & 42600 & 211950 & 4.98 \\ \text { Spain } & 135500 & 32000 & 0.24 \\ \text { Sweden } & 20500 & & 0.00 \\ \text { UK } & 165650 & 80550 & 0.49 \\ \text { USA } & 1429995 & 850880 & 0.59\end{array}$

Sources: Military Balance 2012, and http://en.wikipedia.org/wiki/United_States_Armed_Forces (Jan. 14, 2014) 